\title{
Gas Metal Arc Lap Joining of Aluminium Alloys and Steel Sheets
}

\author{
Atanu Das*, and Amitava De**, \\ *Welding and Joining Science Engineering Department, Chosun University, Gwangju, 61452, Korea \\ **Mechanical Engineering Department, Indian Institute of Technology Bombay, Mumbai, 400076, India \\ †Corresponding author : amit@iitb.ac.in \\ (Received August 28, 2018 ; Revised October 1, 2018 ; Accepted October 11, 2018)
}

\begin{abstract}
A coupled experimental and theoretical investigation on joining of aluminium and galvanized sheets in lap joint geometry using an advanced pulsed current gas metal arc based process is presented. The experimental study was focussed on finding suitable processing conditions to restrict the heat input, and minimize the growth of the phase layer thickness and the formation of Fe-Al intermetallic compounds along the joint interface. The theoretical study included the development of a three-dimensional heat conduction model to compute the temperature field and thermal cycles, and estimate the final joint bead profiles and phase layer thickness as a function of processing conditions. The estimated results are tested extensively for a wide range of experimental conditions. The experimentally measured and the corresponding computed results show that the dissimilar material combinations of aluminium and galvanized steel can be joined successfully by pulsed current gas metal arc with a precise control of processing conditions and heat input.
\end{abstract}

Key Words : Gas metal arc welding, Aluminum alloy, Galvanized steel, Numerical modelling

\section{Introduction}

Mix-material joining of aluminium and steel sheets is a challenging task due to their different melting temperatures, varying material properties, and poor solubility in solid state ${ }^{1)}$. Formation of interface layer with brittle $\mathrm{Fe}-\mathrm{Al}$ intermetallic compounds (IMC) is a major problem and restricting the growth of the same by controlling the heat input has remained the primary goal ${ }^{1,2)}$. The reported literatures suggest that the joint quality can be improved significantly by controlling the heat input $^{3-5)}$. Various methods such as laser beam and laser-arc hybrid joining ${ }^{2,6-14)}$, arc based joining ${ }^{3-5,15-23)}$ and friction stir welding ${ }^{24-26)}$ are employed to join aluminium and steel sheets with an aim to control the heat input during joining of such dissimilar material combinations.

Sierra et al. ${ }^{2)}$ reported a heat input range of 120 to $150 \mathrm{~J} \mathrm{~mm}^{-1}$ for laser beam lap joining of $1 \mathrm{~mm}$ thick AA6016 and $1.2 \mathrm{~mm}$ thick galvanized (GI) steel sheet. Shabadi et al. ${ }^{6}$ joined $1.2 \mathrm{~mm}$ thick AA6016 and $0.7 \mathrm{~mm}$ thick galvanized steel sheets using a heat input of around $45 \mathrm{~J} \mathrm{~mm}^{-1}$. A relatively wider range of heat input e.g. 105 to $165 \mathrm{~J} \mathrm{~mm}^{-1}$ was employed by Zhang et al. ${ }^{9)}$ and Jia et al. ${ }^{10)}$ in laser beam lap joining of aluminium alloy and hot-dip galvanized steel sheets. Windmann et al. ${ }^{11)}$ joined AA6016 and aluminized steel sheets, both of $1.5 \mathrm{~mm}$ thickness, considering a heat input range of around 240 to $330 \mathrm{~J} \mathrm{~mm}^{-1}$. In contrast to laser beam based joining processes, several authors used advanced arc based joining processes that offered superior control of heat input to join aluminium and steel sheets. Murakami et al. ${ }^{15)}$ employed heat input in the range of 170 to $255 \mathrm{~J} \mathrm{~mm}^{-1}$ in pulsed GMA lap joining of $2 \mathrm{~mm}$ thick pure aluminium alloy and uncoated steel sheets. Su et al. ${ }^{16,17)}$ and Kang and $\mathrm{Kim}^{18)}$ employed a typical heat input of around $111 \mathrm{~J} \mathrm{~mm}^{-1}$ to join AA5052 and GI steel sheets in the thickness range of 1.0 to $1.2 \mathrm{~mm}$. Zhang et al. ${ }^{19,20)}$ reported the suitable range of heat input of around 55 to $91 \mathrm{~J} \mathrm{~mm}^{-1}$ for joining of $1 \mathrm{~mm}$ thick aluminium alloy and GI sheets by cold metal transfer (CMT) process. In contrast, Cao et al. ${ }^{3)}$ used a higher heat input of around $200 \mathrm{~J} \mathrm{~mm}^{-1}$ in joining of AA6061 and GI steel sheets. Das et al. ${ }^{5,22}$ used a wide heat input range from 36 to $126 \mathrm{~J} \mathrm{~mm}^{-1}$ for joining aluminium alloys to GI and galvannealed (GA) steel sheets.

The formation and growth of the interface layer and 
the IMCs along the joint interface depend significantly on the peak temperature and resident times during which the interface remains beyond the critical temperatures for the formation of various $\mathrm{Fe}-\mathrm{Al} \mathrm{IMCs}^{13-23)}$. Direct monitoring of the peak temperature and thermal cycles along the joint interface is difficult in laser, arc and laser-arc hybrid joining processes. Murakami et al. ${ }^{15)}$ reported the interface peak temperatures of around 1000 to $1300 \mathrm{~K}$ ( 727 to $1027^{\circ} \mathrm{C}$ ) in joining of aluminium alloy and steel sheets using a GMA based process. Rathod and Kutsuna ${ }^{13)}$ measured the peak temperature of around $1473 \mathrm{~K}\left(1200{ }^{\circ} \mathrm{C}\right)$ in laser beam joining of $1 \mathrm{~mm}$ thick AA5052 and $0.5 \mathrm{~mm}$ thick steel sheets. Peyre et al. ${ }^{27)}$ predicted the interface temperature around 1023 to $1273 \mathrm{~K}$ ( 700 to $1000{ }^{\circ} \mathrm{C}$ ) in laser beam lap joining of aluminium alloy and steel sheet using a heat transfer model. In a laser-hybrid joining process, Meng et al. ${ }^{28)}$ estimated the interface peak temperate to be around $1473 \mathrm{~K}\left(1200{ }^{\circ} \mathrm{C}\right)$. Qin et al. ${ }^{29)}$ predicted the interface peak temperature to be around 1123 to $1373 \mathrm{~K}$ (850 to $1100{ }^{\circ} \mathrm{C}$ ) in a GMA lap joining of aluminium alloy and steel sheets. In contrast, Das et al. ${ }^{23)}$ reported the maximum peak temperature in the range of around 927 $1039 \mathrm{~K}\left(654 \sim 766{ }^{\circ} \mathrm{C}\right)$ for a similar process. In summary, numerical process models for lap joining of aluminium alloy and steel sheets in particular to estimate the temperature field, thermal cycles and bead profiles are rare in open literature.

A three-dimensional heat transfer model to analyse GMA lap joining of aluminium and GI steel sheets is presented in the present work to estimate the temperature profiles, thermal cycles and peak temperature along the joint interface as function of process conditions and joint geometry. The model considers the initial joint bead profile through an analytical approach as function of wire feed rate and joining speed. The computed results are validated extensively with the corresponding experimental results for a wide range of process conditions. The estimated thermal cycles along the joint interface are further used to calculate the growth of the interface layer along the joint interface, which are also validated with the corresponding measured results.

\section{Experimental Setup}

AA5754 and hot-dip galvanized steel sheets, $1 \mathrm{~mm}$ in thickness, were joined in lap configuration using $1 \mathrm{~mm}$ diameter AA4043 filler wire. Table 1 depicts the chemical compositions and tensile strength of the metallic sheets and the filler wire. A microprocessor controlled GMA power source, Alpha Q551, was used to perform the experiments. The sheets were overlapped by $15 \mathrm{~mm}$ with the AA5754 sheet on the top as shown in Fig. 1. The welding torch was positioned along the edge of the aluminium sheet at an angle of $75^{\circ}$ in the direction of joining speed. Pure argon (99.999\%) at a flow rate of $151 \mathrm{~min}^{-1}$ was used as a shielding gas. All the experiments were performed in direct current electrode positive (DCEP) polarity. The range of process variables, shown in Table 2, were selected based on several trial experiments so that sound joint bead profiles could be obtained for all cases within the range of selected parameters. A LEM made (LT 1005-S) current transducer along with a pc-interfaced data acquisition system (Graphtech make, model no. GL 900-4) was employed for monitoring of current and voltage transients at a simultaneous sampling rate of $100 \mathrm{kHz}$.

The thermal cycles were measured using K-type thermocouples located at the bottom of the steel surface along the edge of the AA5754 sheet as indicated by $\mathrm{TC} 1$ in Fig. 1. The joint bead dimensions were meas-

Table 2 Process parameters considered for preparing sample joints

\begin{tabular}{|c|c|c|c|}
\hline $\begin{array}{l}\text { Wire feed rate } \\
\left(\mathrm{w}_{\mathrm{f}}, \mathrm{m} \mathrm{min}^{-1}\right)\end{array}$ & $\begin{array}{l}\text { Current } \\
\left(\mathrm{I}_{\mathrm{AG}}, \mathrm{A}\right)\end{array}$ & $\begin{array}{l}\text { Voltage } \\
\left(\mathrm{V}_{\mathrm{AG}}, \mathrm{V}\right)\end{array}$ & $\begin{array}{c}\text { Joining speed } \\
\left(\mathrm{mm} \mathrm{s}^{-1}\right)\end{array}$ \\
\hline 4.5 & 51.15 & \multirow{4}{*}{$\begin{array}{l}12.08 \sim \\
12.83\end{array}$} & \multirow{3}{*}{$7.5,10.0$} \\
\hline 5.0 & 56.18 & & \\
\hline 5.5 & 61.27 & & \\
\hline 6.0 & 66.20 & & 7.5 \\
\hline
\end{tabular}

Table 1 Chemical composition (in wt\%) of the workpiece materials and filler wire

\begin{tabular}{|c|c|c|c|c|c|c|c|c|c|c|}
\hline & $\mathrm{Mg}$ & $\mathrm{Mn}$ & $\mathrm{Zn}$ & $\mathrm{Fe}$ & $\mathrm{Si}$ & $\mathrm{Cr}$ & $\mathrm{Cu}$ & $\mathrm{Ti}$ & $\mathrm{Al}$ & $\begin{array}{c}\text { UTS } \\
(\mathrm{MPa})\end{array}$ \\
\hline $\mathrm{AA5754}$ & $2.6-3.6$ & 0.50 & 0.20 & 0.40 & 0.40 & 0.30 & 0.10 & 0.15 & Bal. & 245 \\
\hline $\begin{array}{c}\text { AA4043 } \\
\text { (filler wire) }\end{array}$ & 0.05 & 0.05 & 0.10 & 0.80 & $4.5-6.0$ & - & 0.30 & 0.20 & $\mathrm{Bal}$. & 200 \\
\hline & $\mathrm{C}$ & $\mathrm{Mn}$ & $\mathrm{P}$ & $\mathrm{S}$ & $\mathrm{Si}$ & $\mathrm{Cr}$ & $\mathrm{Cu}$ & $\mathrm{Ti}$ & $\mathrm{Al}$ & $\begin{array}{c}\text { UTS } \\
(\mathrm{MPa})\end{array}$ \\
\hline Steel & 0.12 & 0.60 & 0.10 & 0.045 & 0.50 & - & - & 0.30 & - & 330 \\
\hline
\end{tabular}




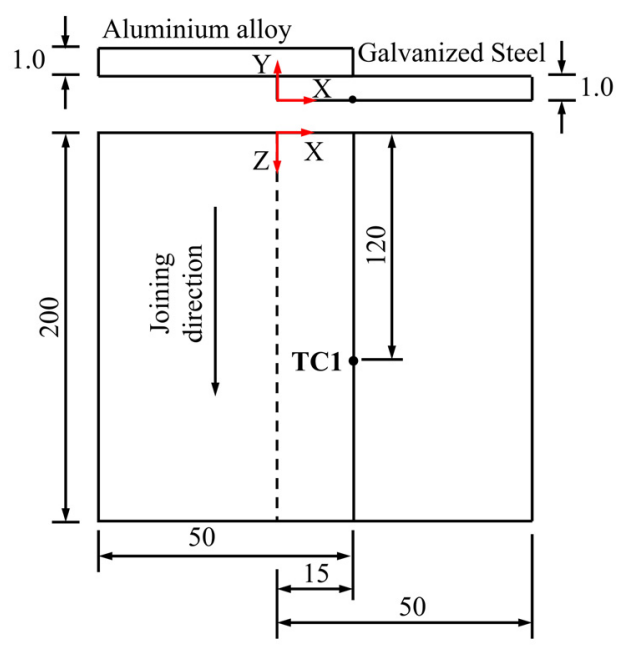

Fig. 1 Schematic picture of arrangement of sheets and thermocouple locations

ured after polishing and etching with Keller's reagent. The Fe-Al interface layer thickness was examined through a CamScan 3200 scanning electron microscopes (SEM). The phases along the joint interface were characterized using energy dispersive spectroscopy (EDS) and Electron Probe Micro-Analyzer (EMPA) based point analysis with an electron spot diameter of $2 \mu \mathrm{m}$. The joint strength was evaluated in a $50 \mathrm{kN}$ universal tensile testing machine (INSTRON 3369) at a crosshead speed of $1 \mathrm{~mm} \mathrm{~min}^{-1}$.

\section{Methodology}

\subsection{Modelling of heat source and filler wire de- position}

A three-dimensional steady state heat conduction analysis was carried out to simulate lap joining of aluminium alloy and GI sheet considering the workpiece moving at a constant speed with respect to a stationary heat source. The governing equation in three-dimensional Cartesian coordinate system can be written as

$$
\frac{\partial}{\partial x}\left(k \frac{\partial T}{\partial x}\right)+\frac{\partial}{\partial y}\left(k \frac{\partial T}{\partial y}\right)+\frac{\partial}{\partial z}\left(k \frac{\partial T}{\partial z}\right)+\dot{Q}=\rho v C_{P} \frac{\partial T}{\partial z}
$$

where, $\rho, C_{P}$ and $k$ referred to respectively the density, specific heat and thermal conductivity; and $\mathrm{T}$ and $\mathrm{v}$ depicted temperature and joining speed, respectively. Eq. (1) considers that the workpiece moves at a constant speed, $\mathrm{v}$, in the negative direction of $\mathrm{z}$-coordinate. The first three terms on the left side of Eq. (1) depicted conductive heat transfer in $\mathrm{x}, \mathrm{y}$ and $\mathrm{z}$ direction. Fig. 2 depicts the boundary conditions considered here that can be represented as

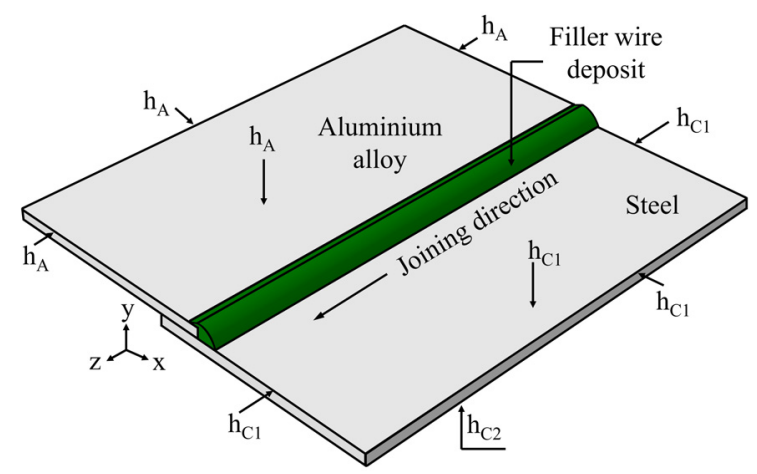

Fig. 2 Boundary conditions applied for steady state analysis

$$
\mathrm{k} \frac{\partial \mathrm{T}}{\partial \mathrm{n}}-\mathrm{q}_{\mathrm{s}}+\mathrm{h}_{\mathrm{C}}\left(\mathrm{T}-\mathrm{T}_{\mathrm{A}}\right)+\sigma \varepsilon\left(\mathrm{T}^{4}-\mathrm{T}_{\mathrm{A}}^{4}\right)=0
$$

where $\mathrm{n}$ referred to the direction normal to surface; $\mathrm{h}_{\mathrm{C}}$, $\varepsilon, \sigma$, and $\mathrm{T}_{\mathrm{A}}$ referred to surface heat transfer co-efficient, emissivity, Stefan-Boltzmann constant and ambient temperature, respectively. The first term (Eq. 2) represented heat loss due to conduction from the surface. The second term $q_{s}$ depicted applied heat flux onto the surface. The third and fourth terms referred to the convective and radiative heat losses from surface to the air.

A lumped heat transfer co-efficient was applied on the steel surfaces that were open to atmosphere as $^{23)}$

$$
\mathrm{h}_{\mathrm{C} 1}=2.4 \times 10^{-3} \varepsilon \mathrm{T}^{1.61}
$$

where $\mathrm{h}_{\mathrm{C} 1}$ was in $\mathrm{W} \mathrm{mm} \mathrm{mm}^{-2} \mathrm{~K}^{-1.61}$, $\mathrm{T}$ was in $\mathrm{K}$ and $\varepsilon$ was 0.32 . Another lumped expression was used for the estimation of heat loss through the backing plate using a temperature dependent convective heat transfer coefficient, $\mathrm{h}_{\mathrm{C} 2}$, as ${ }^{23)}$

$$
\mathrm{h}_{\mathrm{C} 2}=\mathrm{h}_{\mathrm{b}} \times(\mathrm{T}-300)^{0.2}
$$

where $\mathrm{h}_{\mathrm{b}}{ }^{23)}$ was considered as $60 \mathrm{~W} \mathrm{~mm}^{-2} \mathrm{~K}^{-1.2}$. A constant heat transfer coefficient, $\mathrm{h}_{\mathrm{A}}=10 \mathrm{~W} \mathrm{~mm}^{-2} \mathrm{~K}^{-1}$, was applied along the AA5754 sheet surfaces as shown in Fig. $2^{23)}$.

A novel methodology is proposed here to estimate the arc heat source as function of the processing conditions and filler wire deposition. Fig. 3 schematically depicts the volumetric heat source and filler wire deposition that are considered for numerical analysis. The heat input was considered as a uniform volumetric heat source as

$$
\dot{\mathrm{Q}}=\frac{\eta \mathrm{I}_{\mathrm{AG}} \mathrm{V}_{\mathrm{AG}}}{\Pi}
$$

where $\mathrm{I}_{\mathrm{AG}}$ and $\mathrm{V}_{\mathrm{AG}}$ depicted time-averaged welding current and voltage, respectively. The value of $\eta$ was con- 


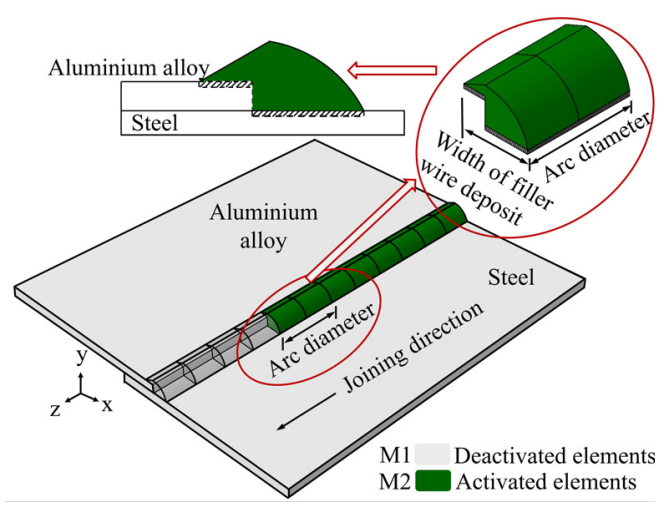

Fig. 3 Representation of the volumetric heat source used in the present work

sidered as $0.70^{23)}$. The denominator term $\Pi$ in equation (5) was estimated as the product of arc diameter and the cross-sectional area including filler wire deposit profile and a small thickness into the metallic sheets as indicated by the cross-hatched section in Fig. 3 underneath the arc.

The deposition from the filler wire was incorporated by addition of a discrete set of elements into the solution domain following element activation and deactivation technique in ANSYS 14.5 as shown in Fig. 3. The deactivated elements were assigned with very low value of thermal conductivity to treat them as thermally insulator. As a set of deactivated elements was activated, the thermo-physical properties of filler wire were assigned to these elements. In Fig. 3, M1 represents the deactivated elements and M2 corresponds to the activated elements depicting deposition from molten filler wire in the current step. The volumetric heat source was applied on the set of activated elements which were lying under the length of arc diameter as shown in Fig. 3. Table 3 shows the thermo-physical properties of the base metals and filler wire.

\subsection{Estimation of filler wire deposit profile and interface layer thickness}

A prior estimation of the expected bead profiles was

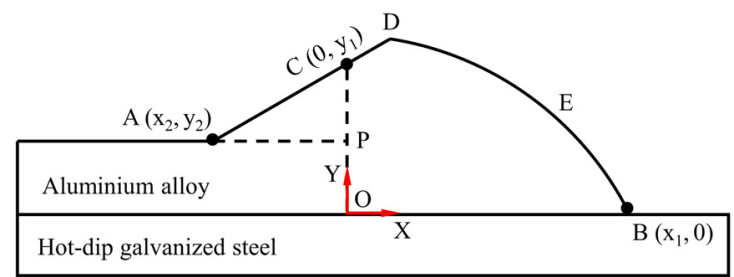

Fig. 4 Schematic diagram of bead profiles for the joint of aluminium and GI sheets

obtained analytically as function of processing conditions and thermo-physical properties of filler alloy to accommodate the discretized geometry for the modelling purpose ${ }^{23)}$. The profile of the bead was presumed as ADB as shown in Fig. 4. The lines AP and OP refer to the original unmelted boundary of the top sheet. The locations of three points, $\mathrm{A}\left(\mathrm{x}_{2}\right), \mathrm{B}\left(\mathrm{x}_{1}\right)$ and $\mathrm{C}\left(\mathrm{y}_{1}\right)$, along the presumed bead profile (in Fig. 4) were estimated analytically as ${ }^{23)}$

$$
\begin{aligned}
& \frac{x_{1}}{d}=7.68811-6.66685 \times 0.87834^{\xi} \\
& \frac{x_{2}}{d}=2.07146-1.68914 \times 0.84153^{\xi} \\
& \frac{y_{1}}{d}=1.76265-0.28662 \times 0.73899^{\xi}
\end{aligned}
$$

where $\xi=\left(\frac{\left(\eta \mathrm{I}_{\mathrm{AG}} \mathrm{V}_{\mathrm{AG}}\right) /\left(\pi \mathrm{r}^{2} \mathrm{v}\right)}{\rho\left[\mathrm{C}_{\mathrm{P}}\left(\mathrm{T}_{\mathrm{L}}-\mathrm{T}_{\mathrm{A}}\right)+\mathrm{L}\right]}\right) \times\left(\frac{2 \mathrm{r}}{\mathrm{b}}\right)$

and $\mathrm{d}, \mathrm{v}$ and $\mathrm{r}$ referred to the filler wire diameter, joining speed and $\operatorname{arc}$ radius, respectively; $\mathrm{T}_{\mathrm{L}}, \mathrm{T}_{\mathrm{A}}$ and $\mathrm{L}$ depicted respectively the liquidus and solidus temperature and latent heat of filler material ${ }^{23)}$. Equation (9) shows $\xi$ is directly related to heat input per unit volume and inversely proportional to thickness of aluminium sheet, $\mathrm{b}^{23)}$. The final bead profile was contemplated based on the numerically computed temperature field as explained in the subsequent sections.

During GMA lap joining of aluminium and GI sheets, the inter-diffusion between $\mathrm{Fe}$ and $\mathrm{Al}$ along the steel surface leads to the formation of an interface layer with

Table 3 Thermo-physical properties of base metals and filler wire

\begin{tabular}{|l|c|c|}
\hline \multicolumn{1}{|c|}{ Property } & AA5754/ AA4043 & Steel \\
\hline Density, $\mathrm{kg} \mathrm{m}^{-3}$ & \multicolumn{1}{|c|}{2680} & 7290 \\
\hline $\begin{array}{l}\text { Liquidus and solidus } \\
\text { temperature, } \mathrm{K}\end{array}$ & \multicolumn{1}{|c|}{925,880} & 1860,1780 \\
\hline Latent heat, $\left(\mathrm{J} \mathrm{kg}{ }^{-1}\right)$ & \multicolumn{1}{|c|}{$3.98 \times 10^{5}$} & $2.7 \times 10^{5}$ \\
\hline $\begin{array}{l}\text { Thermal conductivity, } \\
\mathrm{W} \mathrm{m} \mathrm{K}^{-1}\end{array}$ & $\begin{array}{l}\text { for } \mathrm{T}>925 \mathrm{~K} \\
111.60+0.09 \mathrm{~T}+1.80 \times 10^{-6} \mathrm{~T}^{2} \text { for } 300 \mathrm{~K} \leq \mathrm{T} \leq 925 \mathrm{~K}\end{array}$ & $50-0.04 \mathrm{~T}+2 \times 10^{-5} \mathrm{~T}^{2}$ \\
\hline $\begin{array}{l}\text { Specific heat, } \\
\mathrm{J} \mathrm{kg}^{-1} \mathrm{~K}^{-1}\end{array}$ & $\begin{array}{l}1252 \text { for } \mathrm{T}>925 \mathrm{~K} \\
805.383+0.394 \mathrm{~T}+9.98 \times 10^{-5} \mathrm{~T}^{2} \text { for } 300 \mathrm{~K} \leq \mathrm{T} \leq 925 \mathrm{~K}\end{array}$ & $402.26+0.81 \mathrm{~T}-4.34 \times 10^{-4} \mathrm{~T}^{2}$ \\
\hline
\end{tabular}


several Fe-Al phases. The peak temperature and resident time during which the joint interface remains beyond a critical temperature influences the growth of the phase layer and the types of Fe-Al IMCs. The coefficient of diffusion of $\mathrm{Fe}$ in $\mathrm{Al}$ is much larger than $\mathrm{Al}$ in Fe at temperatures above $793 \mathrm{~K}^{13,23,31)}$. Therefore, the diffusion of $\mathrm{Fe}$ in $\mathrm{Al}$ was considered as negligible below $793 \mathrm{~K}$. The growth of the phase layer was estimated based on the computed thermal cycle at the joint interface using following reference ${ }^{23)}$ and also checked against the corresponding experimentally measured values.

\section{Results and Discussion}

\subsection{Measured current-voltage waveforms}

Fig. 5 shows the measured current and voltage waveforms in GMA joining of aluminium to GI sheets at different wire feed rates of 4.5 and $5.0 \mathrm{~m} \mathrm{~min}^{-1}$. The shortcircuiting period begins with rapid increase in welding current around $150 \mathrm{~A}$ and drop of voltage to a very small value of $0.1 \sim 2 \mathrm{~V}$. At the end of the short- circuiting period, the current is forced to reduce to a small value by digital signal processor to shear-off the molten metal from liquid bridge at a low power resulting in reduction of spatter. A peak current pulse is applied further for a very short duration to facilitate the formation of a droplet at the tip of filler wire that is allowed to grow till it formed a liquid bridge with the steel sheet. In Fig. 5(a) and (b), the average short-circuiting current and time duration were around $67 \mathrm{~A}( \pm 3.5)$ and $3.3 \mathrm{~ms}$ $( \pm 0.23)$, while the arcing current increased from $45.8 \mathrm{~A}$ $( \pm 3.29)$ to $51.75 \mathrm{~A}( \pm 3.39)$ and the arcing duration reduced from $9.15 \mathrm{~ms}( \pm 1.14)$ to $8.47 \mathrm{~ms}( \pm 1.29)$ with the increase of wire feed rate from 4.5 to $5.0 \mathrm{~m} \mathrm{~min}^{-1}$.

\subsection{Computed and corresponding measured bead profiles}

Fig. 6 shows a comparison between the experimentally measured and the corresponding computed bead pro-
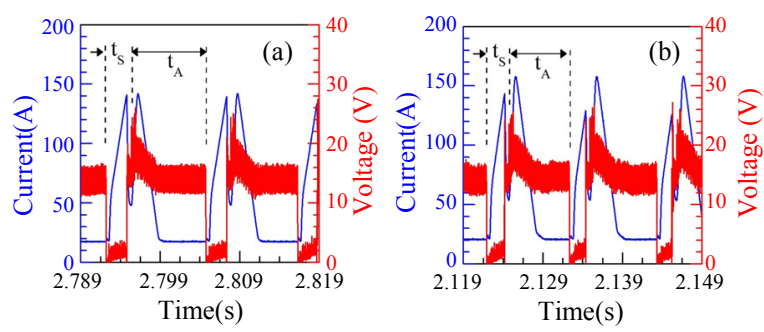

Fig. 5 Measured current and voltage transients for different wire feed rates of (a) 4.5 and (b) $5 \mathrm{~m} \mathrm{~min}^{-1}$. $\mathrm{ts}_{\mathrm{s}}$ and $t_{\mathrm{A}}$ represent short-circuiting and arcing period

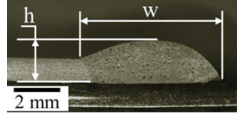

(a)

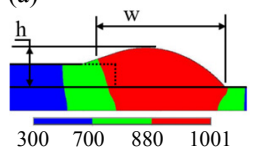

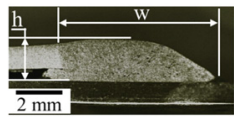

(b)

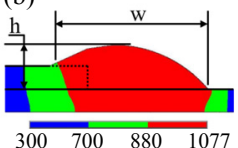

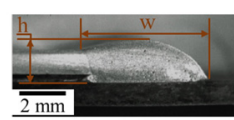

(c)

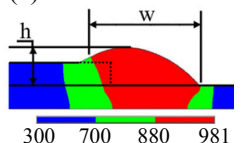

Fig. 6 Comparisons of computed and corresponding measured bead profiles in joining of AA5754 to GI sheet at different wire feed rates $\left(\mathrm{m} \mathrm{min}^{-1}\right)$ and joining speeds $\left(\mathrm{mm} \mathrm{s}^{-1}\right)$ : (a) $(4.5,7.5)$, (b) $(5,7.5)$ and $(\mathrm{c})(5,10)$. The compute and measured values of maximum bead width (w) and bead height (h) are $(\mathrm{mm})$ : (a) $(5.7,6.2)$ and $(1.8,1.8)$, (b) $(6.6$, $7.1)$ and $(1.9,1.8)$ and (c) $(4.7,5.1)$ and $(1.7,1.8)$. Temperature $(\mathrm{K})$ values against the corresponding colour bands are shown below the figures

files for different process conditions as presented in Table 2. The region encompassed between unmelted steel surface and the solidus temperature of aluminium $(880 \mathrm{~K})$ represents the computed bead profile. The maximum bead width of the deposit profile was measured along the AA5754 sheet surface. The computed and corresponding experimentally measured maximum bead widths in Fig. 6 (a) to (c) were as 5.7 and $6.2 \mathrm{~mm}, 6.6$ and $7.1 \mathrm{~mm}$, and 4.7 and $5.1 \mathrm{~mm}$, respectively. The corresponding estimated heat input was as 63.30, 70.69 and $58.77 \mathrm{~J} \mathrm{~mm}^{-1}$, respectively. Likewise, the computed and corresponding measured values of the maximum bead height in Fig. 6(a) to (c) confirmed to around $1.7 \sim 1.9 \mathrm{~mm}$.

A comparison of Fig. 6(a) and (b) showed that increase in heat input as increase in wire feed rate from 4.5 to $5.0 \mathrm{~m} \mathrm{~min}^{-1}$ at a given joining speed of $7.5 \mathrm{~mm} \mathrm{~s}^{-1}$ increased the dimensions of bead profile that was attributed to the increase in filler wire deposition per unit length at higher wire feed rate. In contrast, Fig. 6(b) and (c) depict an increase in joining speed from 7.5 to $10.0 \mathrm{~mm} \mathrm{~s}^{-1}$ at a constant wire feed rate of $5.0 \mathrm{~m} \mathrm{~min}^{-1}$ results in a decrease in the filler wire deposition per unit length and a corresponding decrease in the bead dimensions. In general, Fig. 6(a) to (c) show a fair trend between the computed and the corresponding measured bead profiles in lap joint configuration. Fig. 6 also indicates that the molten deposit forms a fusion joint with aluminium sheet and diffusion bond with GI sheet as the maximum temperature is above the solidus temperature of aluminium and below the liquidus temperature of the steel.

\subsection{Computed and corresponding measured thermal cycles}

Fig. 7(a) shows computed and corresponding measured thermal cycles at thermocouple monitoring loca- 

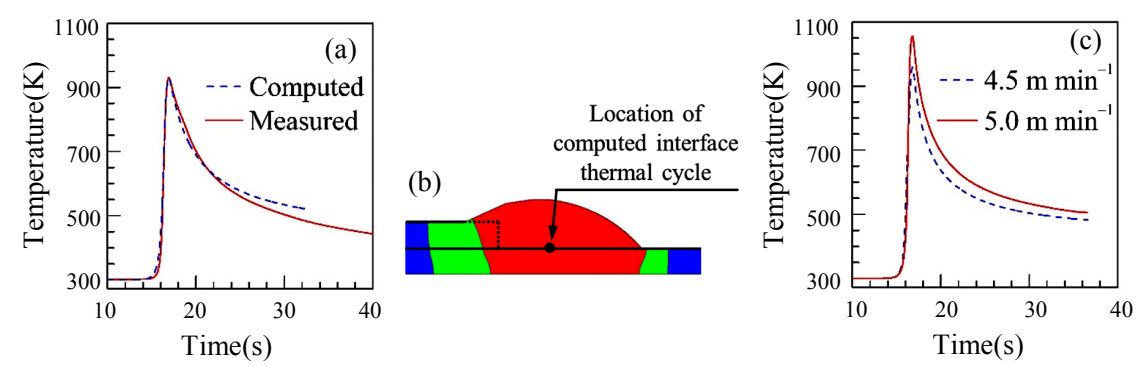

Fig. 7 (a) Comparison of numerically computed and corresponding measured thermal cycles for wire feed rate of $5 \mathrm{~m} \mathrm{~min}^{-1}$ and joining speed of $7.5 \mathrm{~mm} \mathrm{~s}^{-1}$. The computed and measured peak temperatures are $931 \mathrm{~K}$, (b) location of computed interface thermal cycle that experiences maximum peak temperature along the interface, (c) numerically computed interface thermal cycles at constant joining speed of $7.5 \mathrm{~mm} \mathrm{~s}^{-1}$ for different wire feed rates of 4.5 and $5 \mathrm{~m} \mathrm{~min}^{-1}$

tion for wire feed rate of $5.0 \mathrm{~m} \mathrm{~min}^{-1}$ and joining speed of $7.5 \mathrm{~mm} \mathrm{~s}^{-1}$ (Fig. 6b). The computed and the corresponding measured values of peak temperature were $931 \mathrm{~K}$. Fig. 7(a) shows a fair proximity between the computed and the corresponding measured thermal cycles for a specific processing condition. Similar match between the computed and the corresponding experimentally measured thermal cycles are also achieved for all the other processing conditions indicated in Table 2. Fig. 7(b) further shows the location at joint interface that is considered to note the maximum peak temperature for a given process condition and, Fig. 7(c) shows the computed interface thermal cycles at the same location for two different wire feed rates of 4.5 and $5.0 \mathrm{~m} \mathrm{~min}^{-1}$ and a constant joining speed of $7.5 \mathrm{~mm} \mathrm{~s}^{-1}$. The computed peak temperature in Fig. 7(c) increased from 1061 to $965 \mathrm{~K}$ with an increase in wire feed rates from 4.5 to $5.0 \mathrm{~m} \mathrm{~min}^{-1}$.

\subsection{Computed interface peak temperature and corresponding resident time, and estimated and corresponding measured interface phase layer thickness}

Fig. 8(a) shows the computed interface peak temperatures and calculated resident time above $793 \mathrm{~K}$ as function of wire feed rate and joining speed. At a constant speed of $7.5 \mathrm{~mm} \mathrm{~s}^{-1}$, an increase in wire feed rate from 4.5 to $6.0 \mathrm{~m} \mathrm{~min}^{-1}$ resulted in an increase in peak temperature and resident time from 965.3 to $1115.6 \mathrm{~K}$ (marked by inverted triangle) and 2 to $4.4 \mathrm{~s} \mathrm{(marked} \mathrm{by}$ straight triangle), respectively. That could be attributed to rise in heat input at higher wire feed rate. An increase in the wire feed rate from 4.5 to $5.5 \mathrm{~m} \mathrm{mim}^{-1}$ at a highest speed of $10.0 \mathrm{~mm} \mathrm{~s}^{-1}$ led to rise in both the interface peak temperature and resident time respectively from 930.6 to $999 \mathrm{~K}$ (marked by hexagon) and 1.1 to $1.4 \mathrm{~s}$ (marked by pentagon). Fig. 8(a) illustrates that the heat input has a profound influence on the interface peak temperature and resident time. Murakami et al. ${ }^{15)}$ and Qin et al. ${ }^{29)}$ reported similar range of interface peak temperatures of around 1000 to $1300 \mathrm{~K}$ in GMA lap joining of aluminium alloy and steel sheets.

Fig. 8(b) shows the comparison of analytically estimated and corresponding experimentally measured interface phase layer thickness for different joining conditions. Fig. 8(b) depicts increasing wire feed rate from 4.5 to $6.0 \mathrm{~m} \mathrm{~min}^{-1}$ at a constant speed of $7.5 \mathrm{~mm} \mathrm{~s}^{-1}$ increases the analytically estimated phase layer thickness from 1.3 to $4.8 \mu \mathrm{m}$ (marked by circle), and the corresponding experimentally measured layer thickness varies from $2.5( \pm 0.29)$ to $6 \mu \mathrm{m}( \pm 0.37)$ (marked by square). At highest joining speed of $10.0 \mathrm{~mm} \mathrm{~s}^{-1}$, the estimated layer thickness increases from 1 to $2.1 \mu \mathrm{m}$ (marked by star) as an increase in wire feed rate from 4.5 to $5.5 \mathrm{~m} \mathrm{~min}^{-1}$. The corresponding experimentally measured values of layer thickness at the joint interface were increased from $1.7( \pm 0.18)$ to $2.4 \mu \mathrm{m}( \pm 0.30)$ (marked by rhom-
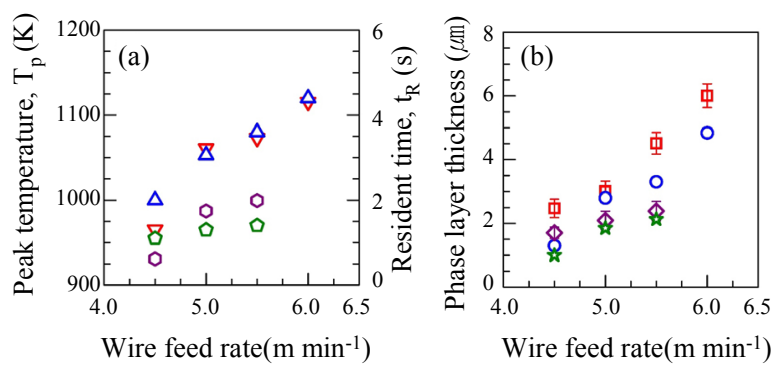

\begin{tabular}{|c|c|c|c|}
\hline $\begin{array}{c}\mathrm{v} \\
\left(\mathrm{mm} \mathrm{s}^{-1}\right)\end{array}$ & $\begin{array}{l}\mathrm{T}_{\mathrm{p}} \\
(\mathrm{K})\end{array}$ & $\begin{array}{l}t_{\mathrm{R}} \\
(\mathrm{s})\end{array}$ & $\underset{(\mu \mathrm{m})}{\mathrm{d}_{\mathrm{E}}}$ \\
\hline 7.5 & $\nabla$ & $\triangle$ & 0 \\
\hline 10.0 & 0 & 0 & $\vec{s}$ \\
\hline
\end{tabular}

Fig. 8 (a) Computed peak temperature and resident time above $793 \mathrm{~K}$ along joint interface as a function of wire feed rate at two different joining speeds (v) of 7.5 and $10 \mathrm{~mm} \mathrm{~s}^{-1}$. (b) Estimated $\left(\mathrm{d}_{\mathrm{E}}\right)$ and corresponding experimentally measured $\left(\mathrm{d}_{\mathrm{M}}\right)$ phase layer thicknesses at two different joining speeds (v) of 7.5 and $10 \mathrm{~mm} \mathrm{~s}^{-1}$ 
bus). Fig. 8(b) shows estimated interface phase layer thickness values are around 0.12 to 0.5 times lower than that of the measured phase layer thickness. The inconsistency between the estimated and the measured layer thicknesses is attributed to neglect the formation of multiple intermetallic compounds and the effect of the same on the growth of layer thickness.

In summary, the GMA lap joining of AA5754 and galvanized steel sheets was found practical with fine control of pulse current parameters to restrict the heat input. A maximum joint strength of around $207 \mathrm{MPa}^{5}$ could be achieved for a wire feed rate of $5 \mathrm{~m} \mathrm{~min}^{-1}$ and welding speed of $10 \mathrm{~mm} \mathrm{~s}^{-1}$ that corresponded to a linear heat input of $58.77 \mathrm{~J} \mathrm{~mm}^{-1}$. It can be noted that the maximum joint strength corresponds nearly $80 \%$ of the ultimate tensile strength of the aluminum base material that is used here. A prior estimation of the adequate heat input and the resulting bead profile, thermal cycles as well as phase layer thickness along the joint interface can be obtained using an appropriately constructed numerical process model as presented in the current work. The computed and the corresponding experimentally measured results that are presented here provide a guideline to examine the suitability of this technology further for real applications in the related user applications.

\section{Conclusion}

A coupled experimental and numerical analysis was carried out in multi-material joining of AA5754 to hot-dip galvanized sheets, both of $1 \mathrm{~mm}$ thickness, by an advanced pulsed current GMA process in lap joint configuration. A novel methodology is used for a heat conduction based thermal analysis of the process that could provide reliable estimate of bead profile, thermal cycles and phase layer thicknesses as function of process conditions, joint geometry and workpiece and filler alloy properties with little simplified assumptions. The growth of the phase layer thickness along the joint interface was estimated considering the progressive solidification of the molten filler wire deposit. The overall results suggest a critical need to control the heat input during joining of aluminium and steel multi-material assembly using arc and laser beam based processes.

\section{Acknowledgement}

Authors would like to acknowledge the support of M/s EWM GmbH for providing the automotive grade aluminium alloy and hot-dip galvanized steel sheets to carry out this research work.
ORCID: Atanu Das: https://orcid.org/0000-0002-7694-4345

ORCID: Amitava De: http://orcid.org/0000-0002-3109-261X

\section{References}

1. L. Agudo, D. Eyidi, C.H. Schmaranzer, E. Arenholz, N. Jank, J. Bruckner and A.R. Pyzalla, Intermetallic $\mathrm{Fe}_{\mathrm{x}} \mathrm{Al}_{\mathrm{y}}$ phases in a steel/Al-alloy fusion weld, Journal of Materials Science, 42(12) (2007), 4205-4214 https://doi.org/10.1007/s10853-006-0644-0

2. G. Sierra, P. Peyre, F.D. Beaume, D. Stuart and G. Fras, Steel to aluminium braze welding by laser process with Al-12Si filler wire, Science and Technology of Welding and Joining, 13(5) (2008), 430-437 https://doi.org/10.1179/174329308X341852

3. R. Cao, J.H. Sun, J.H. Chen and P. Wang, Cold metal transfer joining of aluminum alloys-to-galvanized mild steel, Journal of Materials Processing and Technology, 213(10) (2013), 1753-1763 http://dx.doi.org/10.1016/j.jmatprotec.2013.04.004

4. H.T. Zhang, J.C Feng, P. He, B.B. Zhang, J.M. Chen and L. Wang, The arc characteristics and metal transfer behaviour of cold metal transfer and its use in joining aluminium to zinc-coated steel, Materials Science and Engineering A, 499(1-2) (2009), 111-113 https://doi.org/10.1016/j.msea.2007.11.124

5. A. Das, M. Shome, S.F. Goecke and A. De, Joining of aluminium alloy and galvanized steel using a controlled gas metal arc process, Journal of Manufacturing Processes, 27 (2017), 179-187 https://doi.org/10.1016/j.jmapro.2017.04.006

6. R. Shabadi, M. Suery and A. Deschamps, Characterization of joints between aluminum and galvanized steel sheets, Metallurgical and Materials Transactions A, 44A(6) (2013), 2672-2682 https://doi.org/10.1007/s11661-012-1605-7

7. C. Dharmendra, K.P. Rao, J. Wilden and S. Reich, Study on laser welding-brazing of zinc coated steel to aluminum alloy with a zinc based filler, Materials Science and Engineering A, 528(3) (2011), 1497-1503 https://doi.org/10.1016/j.msea.2010.10.050

8. C. Thomy and F. Vollertsen, Laser-MIG hybrid welding of aluminium to steel-effect of process parameters on joint properties, Welding in the World, 56(5-6) (2012), 124-132 https://doi.org/10.1007/BF03321356

9. M.J. Zhang, G.Y. Chen, Y. Zhang and K.R. Wu, Research on microstructure and mechanical properties of laser keyhole welding-brazing of automotive galvanized steel to aluminum alloy, Materials and Design, 45 (2013), 24-30 https://doi.org/10.1016/j.matdes.2012.09.023

10. L. Jia, J. Shichun, S. Yan, N. Cong, C. Junke and H. Genzhe, Effects of zinc on the laser welding of an aluminum alloy and galvanized steel, Journal of Materials Processing and Technology, 224 (2015), 49-59 
https://doi.org/10.1016/j.jmatprotec.2015.04.017

11. M. Windmann, A. Rottger, H. Kugler, W. Theisen and F. Vollertsen, Laser beam welding of aluminum to Al-base coated high-strength steel 22MnB5, Journal of Materials Processing and Technology, 217 (2015), 88-95 https://doi.org/10.1016/j.jmatprotec.2014.10.026

12. R. Borrisutthekul, T. Yachi, Y. Miyashita and Y. Mutoh, Suppression of intermetallic reaction layer formation by controlling heat flow in dissimilar joining of steel and aluminium alloy, Materials Science and Engineering A, 467(1-2) (2007), 108-113 https://doi.org/10.1016/j.msea.2007.03.049

13. M.J. Rathod and M. Kutsuna, Joining of aluminum alloy 5052 and low-carbon steel by laser roll welding, Welding Journal, 83(1) (2004), 16s-26s.

14. M. Gao, C. Chen, S. Mei, L. Wang and X. Zeng, Parameter optimization and mechanism of laser-arc hybrid welding of dissimilar Al alloy and stainless steel, The International Journal of Advanced Manufacturing Technology, 74(1-4) (2014), 199-208 https://doi.org/10.1007/s00170-014-5996-z

15. T. Murakami, K. Nakata, H. Tong and M. Ushio, Dissimilar metal joining of aluminum to steel by MIG arc brazing using flux cored wire, ISIJ International, 43(10) (2003), 1596-1602

16. Y. Su, X. Hua and Y. Wu, Effect of input current modes on intermetallic layer and mechanical property of aluminum-steel lap joint obtained by gas metal arc welding, Materials Science and Engineering A, 578 (2013), 340-345 https://doi.org/10.1016/j.msea.2013.04.097

17. Y. Su, X. Hua and Y. Wu, Influence in alloy elements on microstructure and mechanical property of aluminum-steel lap joint made by gas metal arc welding, Journal of Materials Processing and Technology, 214(4) (2014), 750-755 https://doi.org/10.1016/j.jmatprotec.2013.11.022

18. M. Kang and C. Kim, Joining Al 5052 alloy to aluminized steel sheet using cold metal transfer process, Materials and Design, 81 (2015), 95-103 https://doi.org/10.1016/j.matdes.2015.05.035

19. H.T. Zhang, J.C. Feng, P. He and H. Hackl, Interfacial microstructure and mechanical properties of aluminium-zinc-coated steel joints made by a modified metal inert gas welding-brazing process, Materials Characterization, 58 (2007) 588-592

https://doi.org/10.1016/j.matchar.2006.07.008

20. H.T. Zhang, J.C. Feng and P. He, Interfacial phenomena of cold metal transfer (CMT) welding of zinc coated steel and wrought aluminium, Materials Science and Technology, 24(11) (2008) 1346-1349 https://doi.org/10.1179/174328407X213152

21. H. Zhang and J. Liu, Microstructure characteristics and mechanical property of aluminum alloy/stainless steel lap joints fabricated by MIG welding-brazing process,
Materials Science and Engineering A, 528(19-20) (2011), 6179-6185

https://doi.org/10.1016/j.msea.2011.04.039

22. A. Das, M. Shome, C.R. Das, S.F. Goecke and A. De, Joining of galvannealed steel and aluminium alloy using controlled short circuiting gas metal arc welding process, Science and Technology of Welding and Joining, 20(5) (2015), 402-408 https://doi.org/10.1179/1362171815Y.0000000032

23. A. Das, M, Shome, S.F. Goecke and A. De, Numerical modelling of gas metal arc joining of aluminium alloy and galvanized steels in lap joint configuration, Science and Technology of Welding and Joining, 21(4) (2016), 303-309 https://doi.org/10.1080/13621718.2015.1104206

24. A. Elrefaey, M. Gouda, M. Takahashi and K. Ikeuchi, Characterization of aluminum/steel lap joint by friction stir welding, Journal of Materials Engineering and Performance, 14(1) (2005), 10-17 https://doi.org/10.1361/10599490522310

25. K. Kimapong and T. Watanabe, Lap joint of A5083 aluminum alloy and SS400 steel by friction stir welding, Materials Transactions, 46(4) (2005), 835-841 https://doi.org/10.2320/matertrans.46.835

26. Y.C. Chen and K. Nakata, Effect of the surface state of steel on the microstructure and mechanical properties of dissimilar metal lap joints of aluminum and steel by friction stir welding, Metallurgical and Materials Transactions A, 39A (2008), 1985-1992 https://doi.org/10.1007/s11661-008-9523-4

27. P. Peyre, G. Sierra, F.D. Beaume, D. Stuart and G. Fras, Generation of aluminium-steel joints with laser-induced reactive wetting, Materials Science and Engineering A, 444(1-2) (2007), 327-338 https://doi.org/10.1016/j.msea.2006.09.111

28. X. Meng, G. Qin, Y. Su, B. Fu and Y. Ji, Numerical simulation of large spot laser + MIG arc brazing- fusion welding of Al alloy to galvanized steel, Journal of Materials Processing and Technology, 222 (2015), 307-314 https://doi.org/10.1016/j.jmatprotec.2015.03.020

29. G. Qin, Y. Su, X. Meng and B. Fu, Numerical simulation on MIG arc brazing-fusion welding of aluminum alloy to galvanized steel plate, The International Journal of Advanced Manufacturing Technology, 78 (9-12) (2015), 1917 -1925 https://doi.org/10.1007/s00170-014-6529-5

30. S. Kobayashi and T. Yakou, Control of intermetallic compound layers at interface between steel and aluminum by diffusion-treatment, Materials Science and Engineering A, 338(1-2) (2002), 44-53 https://doi.org/10.1016/S0921-5093(02)00053-9

31. H. Mehrer, Diffusion in solid metals and alloy, Numerical data and functional relationship in science and technology, Springer Verlag, Berlin, 26 (1990), 129-152 